Characterization of concrete hardness by using sugarcane bagasse waste mixture by carbon oven curing process

Agus Rino, Farida, Elvaswer, and Dahyunir Dahlan

Citation: 1801, 040005 (2017); doi: 10.1063/1.4973094

View online: http://dx.doi.org/10.1063/1.4973094

View Table of Contents: http://aip.scitation.org/toc/apc/1801/1

Published by the American Institute of Physics 


\title{
Characterization of Concrete Hardness by Using Sugarcane Bagasse Waste Mixture by Carbon Oven Curing Process
}

\author{
Agus Rino ${ }^{1, a)}$, Farida ${ }^{2}$, Elvaswer $^{3}$ and Dahyunir Dahlan ${ }^{3}$ \\ ${ }^{1}$ Physics Department, STKIP PGRI Sumatera Barat, 25137 Indonesia \\ ${ }^{2}$ Geographycs Department, STKIP PGRI Sumatera Barat, 25137 Indonesia \\ ${ }^{3}$ Physics Department, Andalas University, Sumatera Barat, 25137 Indonesia \\ ${ }^{a)}$ Corresponding author: Agusrino8@gmail.com
}

\begin{abstract}
Sugarcane bagasse is one of the solid waste that can be processed as a mixture of structure materials. In the previous research, sugarcane bagasse has been processed and used as a mixture of portland cement, the manufacture of asbestos and also mixtures for manufacturing of brake pads that are frequently used in motor vehicle. Based on the previous research results, it is strongly necessary to develop a research about sugarcane bagasse for structure materials. The method used to determine the mechanical properties is tensile test and compression test. To obtain the intensity of material variations, it is needed to make various sizes of filtration carbon in the form of aggregate that is mixed into the tiles material. The size of the aggregate used in concrete material can be on $200 \mu \mathrm{m}, 400 \mu \mathrm{m}$ and $600 \mu \mathrm{m}$. This measure is taken in accordance with the size of the filtration apparatus. Furthermore, in obtaining sugarcane bagasse carbon, the researcher must do the oven curing process on $200{ }^{\circ} \mathrm{C}$ temperature and 3 hours in curing oven. In this research the best result is used bagasse powder mixtured $200 \mu \mathrm{m}$ is $7.2 \mathrm{MPa}$.
\end{abstract}

\section{INTRODUCTION}

\section{Sugarcane Bagasse}

Sugarcane is classified into Gramineae tribe or types of grasses that have harvest time between three to four months. The result of sugarcane harvest is usually used for the manufacture of sugar by extracting liquid or liquid contained in the stalks of sugarcane so that the fiber and the contents are separated and as a result, that produces waste that is known as bagasse. Untreated well bagasse will be solid waste and causing pollution as well as damaging the healthy environment. In previous studies, bagasse was processed into environmentally friendly materials and appropriate products. Bagasse is a natural fiber that is easily obtained and widely used as an ingredient for the manufacture of a product, such as the manufacture of particleboards, furniture and polymer blending substance [1,2]. Bagasse is a natural fiber which contains cellulose and many chemical compounds. Chemical compounds in the composition of cement consist of $\mathrm{SiO}_{2}$ by $20,32 \%, 4.20 \% \mathrm{Al}_{2} \mathrm{O}_{3}, 5.56 \% \mathrm{Fe}_{2} \mathrm{O}_{3}, \mathrm{CaO} 63.96 \%$, $\mathrm{MgO} 1.13 \%, 1.57 \% \mathrm{SO}_{3}$ and other chemical compounds for about $4 \%$. Bagasse is a natural fiber that can be utilized as additional alternative materials to improve the strength of cement composition [3].Carbon or ash that is derived from the combustion of bagasse can be used as an additive mixture of material and may affect the bond strength of chemical compounds in the cement [4]. Researchers had previously been utilizing carbon waste of burned bagasse as an alternative material for the manufacture of motor vehicle brake pads as shown in Figure 1 [5]. According to previous research results, waste bagasse-based research methods with oven curing process should be developed further. The purpose of this study was to determine the physical properties and strength of materials. To determine the physical properties and the strength of the material, what needs to be done is to test the material characterization press so that variations in material strengths of both methods. How mechanical properties of materials when that are used as an ingredient in concrete?!. Very strong concrete are very useful for building structures, bridges and highways.

The 6th International Conference on Theoretical and Applied Physics (The 6th ICTAP)

AIP Conf. Proc. 1801, 040005-1-040005-5; doi: 10.1063/1.4973094

Published by AIP Publishing. 978-0-7354-1469-3/\$30.00 


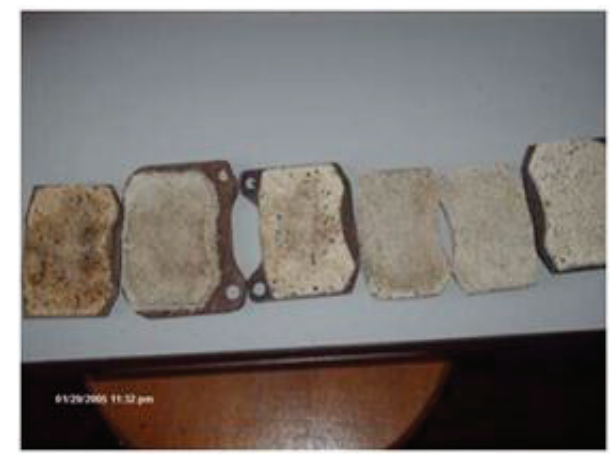

FIGURE 1. The brake pads with a mixture of waste bagasse.

\section{MATERIAL AND METHODS}

\section{Raw Material Collected}

Bagasse sugarcanes are collected from traders who were available around campus and nearby locations. Bagasse was cleaned and washed with water to remove the stain or dirt on the material. Then, bagasse was dried conventionally for one week. After bagasse was dried, then the bagasse was crushed by using agricultural cutting machine to form small pieces that resemble the fibers as seen in Figure 2, tiny bits of bagasse used as the base material for the curing process.

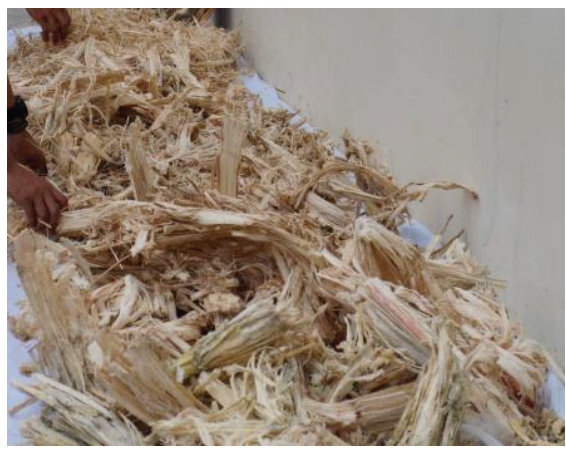

(a)

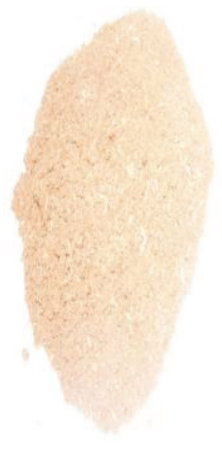

(b)

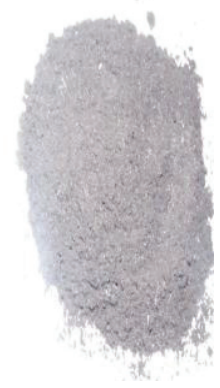

FIGURE 2. (a) Bagasse as raw material, (b) Bagasse powder was milled

\section{Experiment Design and Tile Manufacturing}

Bagasse that had been cut by agricultural products cutting machine will resemble tiny fibers, then the fibers were cured with a temperature of $200^{\circ} \mathrm{C}$ for three hours so the bagasse color changes due to the influence of the temperature. After conducting the curing process, then, the bagasse was finely ground into powder form. Powder bagasse was filtered by using sieve that has various sizes among $200 \mu \mathrm{m}, 400 \mu \mathrm{m}$ and $600 \mu \mathrm{m}$ Powder bagasse is used as an additive in the manufacture of tiles or concrete.. In this study, the additives that are added into the mix of the tiles are as much as $5 \%$ of the composition of the material volume. The composition of the tile material consisting of cement, sand, gravel and water reach a total volume of $1600 \mathrm{ml}$ and a ratio of $1: 2: 1: 1$. All ingredients are mixed as the basic composition of manufacture tiles. The process of making tiles is designed with laboratory scale, which is better known as the prototype scale. The size of the tiles that are made in this study has length of 15 $\mathrm{cm}$ and width of $10 \mathrm{~cm}$ as shown in Figure 3. This measure is taken in order to make the printed material can be more quickly dried; consequently, the hardness testing process can be done as soon as possible. This test was conducted to determine and characterize the strength of concrete materials that are made from a mix of waste bagasse; therefore, physical properties of the concrete material interplanted with waste bagasse can be recognized. 


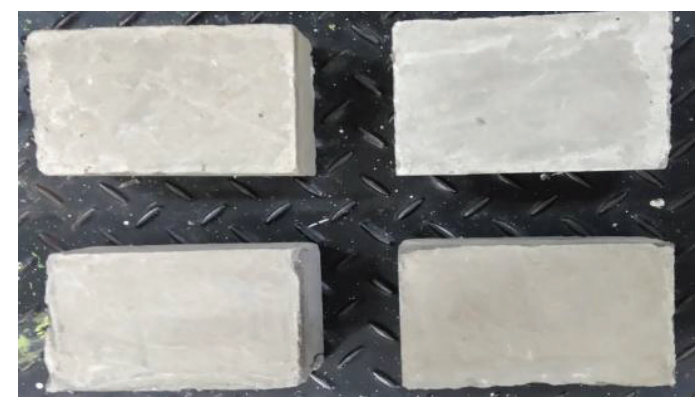

FIGURE 3. Produced samples used bagasse powder mixture

\section{Method of Characterization and Hardness Testing}

Making bagasse powder has been processed using Ball Milling for 300 rounds so that the output of milling gives smoother result. Powder that has been destroyed by ball milling sieved in accordance with the required standards. The result of the filtering is used as a resin for mortar and then printed in accordance with the expected size of the tiles. The printed tiles are then dried in a few days but to speed up the drying process and reduce the water content of the tiles so that the concrete material incorporated into the curing oven for 8 hours at a temperature of $50{ }^{\circ} \mathrm{C}$.

The dried tiles will be tested using hardness tester press materials such as iron cylinder with a diameter of $20 \mathrm{~cm}$ with load of $3000 \mathrm{kgs}$ as shown at figure 4 .

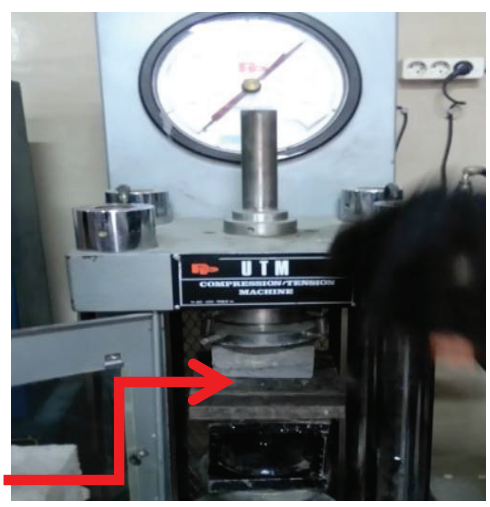

FIGURE 4. Tension Machine for Strength Tester

\section{RESULT AND DISCUSSION}

Utilization of waste bagasse (bagasse) as a compound for concrete has been done by using a compression test. Material strength of each bagasse powder sieve is shown in Figure 5.

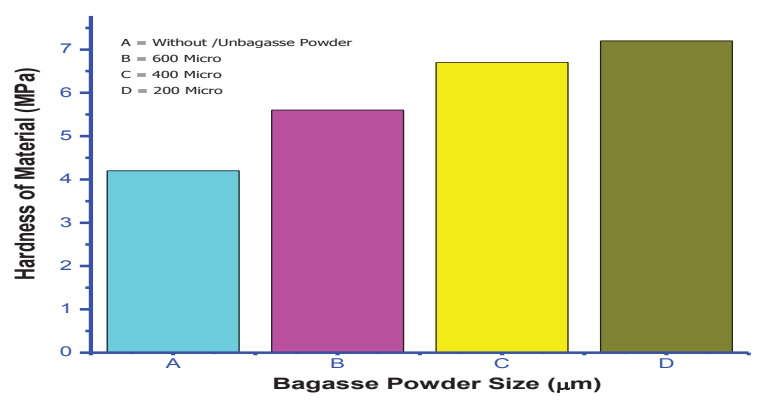

FIGURE 5. Relationship Hardness the size of the carbon powder material 
The graph shows that the strength of concrete without extra or mixed bagasse (conventional) provides a strength of 4.2 MPa. The size of sieve affects the strength of the material. When it was used in a mixture of bagasse (Carbon) powder with a size of $600 \mu \mathrm{m}$, it gives concrete strength of $5.6 \mathrm{MPa}$, the size of $400 \mu \mathrm{m}$ giving strength of $6.7 \mathrm{MPa}$ and use of the powder with a size of $200 \mu \mathrm{m}$ gives strength to the concrete at $7.2 \mathrm{MPa}$.

The addition of carbon powder in concrete affects the strength of the material. Increased material strength of concrete that is caused by carbon granules can cover the fine pores or cavities concrete, so that concrete will be more dense and tight. The addition of carbon powder in the mixture of concrete will affect the texture of the concrete material. The experiment shows that the concrete material with a mixture of carbon powder showed a more slippery surface texture and smooth and shiny when compared to conventional concrete. The use of carbon fine powder can increase the particle holding capacity so that the concrete material is compacted and it has no gaps. One of the concrete strength is caused by dense arrangement of particles within the material. The density of the particles was also influenced by the holding capacity of each material particle. The addition of a mixture of materials can affect the physical properties of the concrete as it can be seen when given a mixture of the finer the texture of the surface becomes darker shiny and slippery. Texture of the concrete material looked shiny because of the effect of the carbon powder with a height of temperature and long curing time. The concrete material that is made from a mixture of Carbon Powder with the curing process is able to bind the aggregate, so that the composition of the particles in the structure becomes denser without pore. Concrete strength test results can be seen in Table I.

TABLE 1. Results of Material Strength Test with a mixture of Carbon Powder

\begin{tabular}{ccccc}
\hline No & $\begin{array}{c}\text { Square of material } \\
\left(\mathrm{mm}^{2}\right)\end{array}$ & $\begin{array}{c}\text { Carbon Powder size } \\
(\mu \mathrm{m})\end{array}$ & $\begin{array}{c}\text { Force of Machine } \\
(\mathrm{N})\end{array}$ & $\begin{array}{c}\text { Strength of material } \\
\left(\mathrm{Kg} / \mathrm{mm}^{2}\right)\end{array}$ \\
\hline 1 & 15000 & - & 60000 & 0.42 \\
2 & 15000 & $600 \mu \mathrm{m}$ & 85000 & 0.56 \\
3 & 15000 & $400 \mu \mathrm{m}$ & 100000 & 0.67 \\
4 & 15000 & $200 \mu \mathrm{m}$ & 105000 & 0.72 \\
\hline
\end{tabular}

\section{CONCLUSION}

The results of this experimental research showed that the addition of carbon powder can affect the strength of the material. The smaller or fine the size of the carbon powder used in the mix then thebetter strength it can give because the carbon powder that is refined can be quicker and easier to fill the cavities or pores. As a result, the concrete becomes denser and the structure of the bond can be tighter. Density of the particles arrangement can greatly affect the strength of the concrete material. Material that does not have a gap provides better strength than the material gaps. This is evident from the results of tensile test as shown in Table I. Conventional Concrete / without additional carbon powder has a physical form that is more rough and hollow, as do the pressure test, hollow concrete more easily broken with a strength of 4.2 MPa. Coarse carbon powder did not affect the power of this because aggregate concrete cannot bind the particles perfectly; thus, it gives little influence toward the material. This research can be developed using the sieve and pieces that have more subtle differences so the hardness and strength of concrete designed can be seen. As shown in Figure 5, the level of the concrete strength is influenced by the level of the roughness of carbon powder in which the use of carbon powder with a size of $600 \mu \mathrm{m}$ give strength of 5.6 Mpa, while bagase powder with a size of $400 \mu \mathrm{m}$ gives strength of $6.7 \mathrm{MPa}$ and $200 \mu \mathrm{m}$ gives a strength of 7,2 M.Pa.

\section{ACKNOWLEDGMENT}

Infinite acknowledgements go to Kemenristek - Higher Education that has helped researchers in the form of funds and support in this study. Besides, we also would like to thank Mazuki, Ph.D as Chairman of the Department of Physics, Andalas University who have facilitated this research.

\section{REFERENCES}

1. X. Xu, F. Yao, Q. Wu, and D. Zhou, "The influence of wax-sizing on dimension stability and 2 mechanical properties of bagasse particleboard," pp. 6-11, 2007.

2. C. F. Liu, R. C. Sun, W. Luo, and Z. N. Cao, "Succinoylation of sugarcane bagasse under ultrasound 
irradiation," vol. 99, pp. 1465-1473, 2008.

3. M. J. Ghazali, C. H. Azhari, S. Abdullah, M. Z. Omar, and a S. Materials, "Characterisation of Natural Fibres ( Sugarcane Bagasse ) in Cement Composites," in Engineering, 2008, vol. II, pp. 3-5.

4. O. D. E. Paula, F. Tinôco, I. D. E. Fátima, C. De, O. Saraz, J. Alexander, S. Bagasse, A. S. H. As, and M. O. D. E. Paula, "Sugarcane Bagasse Ash as a Partial Portland Cement Replacement Material Portland," 2010.

5. U. Akadike, S. B. Hassan, F. Asuke, and J. O. Agunsoye, "Development of Asbestos - Free Brake Pad Using Bagasse," vol. 32, no. 1, 2010. 